AperTO - Archivio Istituzionale Open Access dell'Università di Torino

Interactive transmission of two phytoplasmas by the vector insect

This is a pre print version of the following article:

Original Citation:

Availability:

This version is available http://hdl.handle.net/2318/152811

since 2016-07-25T09:29:17Z

Published version:

DOI:10.1111/aab.12146

Terms of use:

Open Access

Anyone can freely access the full text of works made available as "Open Access". Works made available under a Creative Commons license can be used according to the terms and conditions of said license. Use of all other works requires consent of the right holder (author or publisher) if not exempted from copyright protection by the applicable law. 


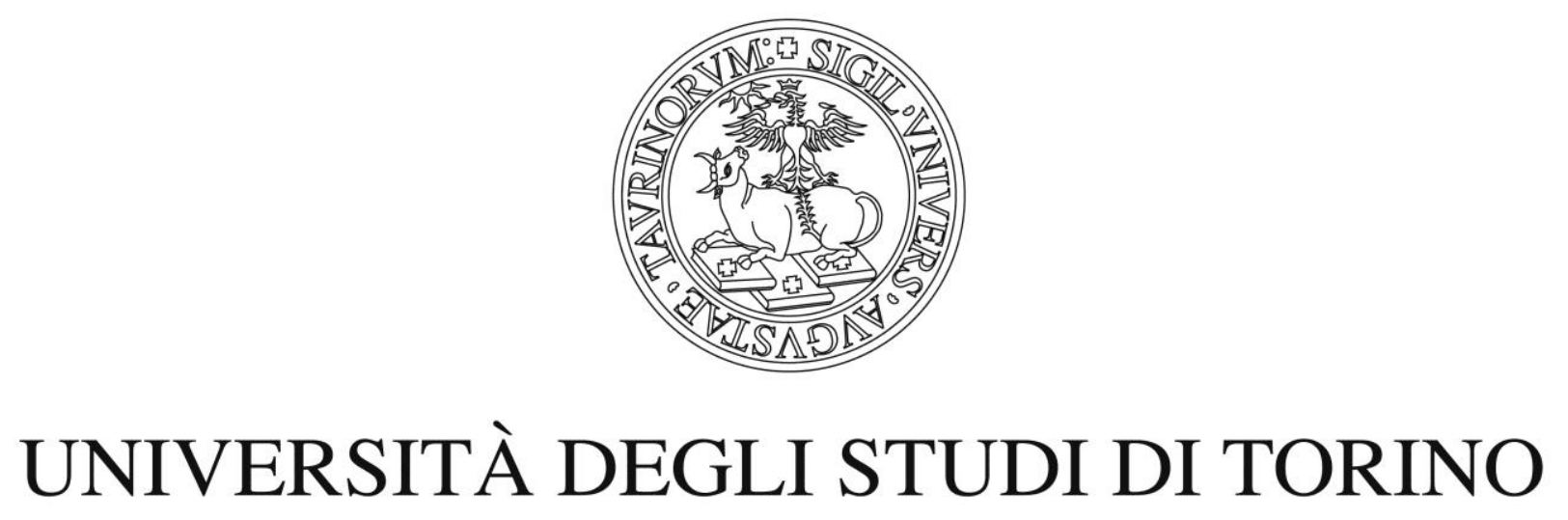

This is the accepted version of the following article: [3. Rashidi M., D'Amelio R., Galetto L., Marzachì C., and Bosco D., 2014. Interactive transmission of two phytoplasmas by the vector insect. Annals of Applied Biology, 165: 404-413.], which has been published in final form at [doi:10.1111/aab.12146] 
ANNALS OF

APPLIED BIOLOGY

\section{Interactive transmission of two phytoplasmas by the vector insect}

\begin{tabular}{|r|l|}
\hline Journal: & Annals of Applied Biology \\
\hline Manuscript ID: & AAB-2013-0321.R1 \\
\hline Manuscript Type: & Research paper \\
\hline Date Submitted by the Author: & n/a \\
\hline Complete List of Authors: & $\begin{array}{l}\text { Rashidi, Mahnaz; Consiglio Nazionale delle Ricerche, CNR, Istituto di } \\
\text { Virologia Vegetale } \\
\text { D'Amelio, Romina; Universita di Torino, DISAFA - Entomologia } \\
\text { Galetto, Luciana; Consiglio Nazionale delle Ricerche, CNR, Istituto di } \\
\text { Virologia Vegetale } \\
\text { Marzachi, Cristina; Consiglio Nazionale delle Ricerche, CNR, Istituto di } \\
\text { Virologia Vegetale } \\
\text { Bosco, Domenico; Universita di Torino, DISAFA - Entomologia }\end{array}$ \\
\hline Key Words: & \begin{tabular}{l} 
Phytoplasmas, Transmission By Vectors, Entomology \\
\hline
\end{tabular} \\
\hline
\end{tabular}

SCHOLARONE"

Manuscripts 
1

2

3

4

5

6

7

8

9

10

11

12

13

14

15

16

17

18

19

20

21

22

23

24

25

26

27

28

29

30

31

32

33

34

35

36

37

38

39

40

41

42

43

44

45

46

47

48

49

50

51

52

53

54

55

56

57

58

59

60

\section{Interactive transmission of two phytoplasmas by the vector insect}

2

3

Rashidi M. ${ }^{1,2^{*}}$, D’Amelio R. ${ }^{1^{*}}$, Galetto L. ${ }^{2}$, Marzachì C. ${ }^{2}$, and Bosco D..$^{1^{*}}$

4

$5 \quad{ }^{1}$ University of Torino, DISAFA, Largo Paolo Braccini 2, 10095 Grugliasco (TO), Italy.

$6 \quad{ }^{2}$ Istituto di Virologia Vegetale, CNR, Strada delle Cacce 73, 10135 Torino, Italy.

7

8 *the two authors equally contributed to the paper

9

10 "Corresponding author: Domenico Bosco, University of Torino DISAFA, Largo Paolo Braccini 2,

11 Grugliasco (TO), Italy, tel. +39 011 6708529, fax +39 011 670853, domenico.bosco@unito.it

12

13 Running title: CYP and FDP competition in E. variegatus

14 


\section{Abstract}

16 Phytoplasmas are wall-less bacteria associated with many plant diseases of wild and cultivated plants, transmitted by hemipteran insects. In nature, vectors can acquire more than one phytoplasma by feeding on multiple-infected source plants or sequentially on plants infected by different phytoplasmas. The acquisition

19 of multiple phytoplasmas may lead to their interaction in the insects. In this work, nymphs of the leafhopper

20 Euscelidius variegatus were allowed to feed sequentially on Flavescence dorée (FDP)-infected and

21 chrysanthemum yellows (CYP)-infected source plants and vice-versa. Following the acquisition feeding, the titre of the two phytoplasmas in the insect was measured over time. FDP and CYP transmission capability of the doubly-infected leafhoppers was studied by transmission to Vicia faba L., and to artificial feeding medium. Both phytoplasmas were acquired by the vector regardless of the feeding order and FDP titre, but not CYP titre, which was affected by double infection. FDP and CYP persisted in the insect for life. Only CYP was consistently and efficiently transmitted by doubly-infected leafhoppers. Consistently, FDP was seldom detected in the salivary glands and never in the artificial feeding medium of doubly-infected leafhoppers. In conclusion, competition between CYP and FDP affected only salivary gland colonization, while it had almost no effect on phytoplasma acquisition. Competition among phytoplasma strains in an evolutionary time scale may explain the greater ability of CYP to colonize the insect body and be transmitted. 
43 broad or a restricted plant host range (Foissac and Wilson, 2010), and they can be transmitted by polyphagous or monophagous insects (Weintraub and Beanland, 2006). Once infected, vectors remain inoculative for life (Bosco and D'Amelio, 2010), and for these reasons transmission by the vector is by far the most important route of phytoplasma dispersion and a key element in the epidemiology of these vectorborne pathogens (Gratz, 1999; Bosco and D’Amelio, 2010).

In nature, insect vectors can potentially acquire more than one phytoplasma species by feeding sequentially on plants infected by different phytoplasmas or by feeding on multiply-infected plants. Mixed phytoplasma infections are known in several plant species (Lee et al., 2000; Marzachi et al., 2001; Roggia et al., 2013), and competition between different phytoplasmas within the same plant has been described only for few closely related phytoplasma strains (Kuske and Kirkpatrick, 1992; Sinclair et al., 2000; Seemuller et al., 2010). In contrast, mixed phytoplasma infection in the vector have been only sporadically reported.

Phytoplasma interactions in the vector insects may result in interactive (enhanced or suppressed) or noninteractive (independent) transmission of the two agents (reviewed in Bosco and D'Amelio, 2010). Generally, the interference is most pronounced between closely related strains of the same pathogen (Purcell, 1982). In this case the interaction results in lack of transmission of one of the strains or in a transmission pattern where the strain acquired first is also the first and most efficiently transmitted (Freitag,1967). Moreover, some suppressive interactions have been observed between phytoplasmas and other plant pathogens such as spiroplasmas (Maramorosch, 1958, De Oliveira et al., 2007) and viruses (Hsu and Banttari, 1979). The interaction between aster yellows phytoplasma and oat blue dwarf virus (OBDV, Tymoviridae) by the vector Macrosteles quadrilineatus Forbes (= fascifrons) results in a decrease of the transmission rate of both pathogens (Hsu and Banttari, 1979), and the interaction between corn stunt spiroplasma and maize bushy stunt phytoplasma within the vector Dalbulus maidis results in the suppression of phytoplasma transmission ("unilateral cross-protection") when spiroplasma acquisition preceeds that of phytoplasma (Maramorosch, 1958; de Oliveira et al., 2007). 
70 al., 1970), and preliminary experiments have shown that it can acquire both phytoplasmas in mixed

71 infections (D'Amelio et al., 2007).

72 The aims of the work were to describe the competition between two genetically unrelated phytoplasmas

73 (CYP and FDP) in the common vector E. variegatus, and provide details on the acquisition, multiplication

74 and transmission pattern of the competing pathogens. For the first time, interactions between different

75 phytoplasmas in the same vector are studied in detail using molecular tools that allow detection and

76 quantification of phytoplasmas in the insect body. In competition experiments, transmission assays provided

77 information on the interaction between CYP and FDP, while molecular detection in the whole body and in

78 the dissected organs as well as in artificial feeding media explained some aspects of their competition.

79

80

81

82

83

84

85

86

87

88

89

90

91

92

93

94

95

96

97

\section{Materials and methods}

Phytoplasma isolates, host plants and insect vector

Two phytoplasmas were used in this study, chrysanthemum yellows phytoplasma (CYP, a strain of the Candidatus Phytoplasma asteris, 16SrI-B genetic group originally found in the Italian Riviera (Conti et al., 1988), and Flavescence dorée phytoplasma (FDP), 16SrV-D (Martini et al., 2002), kindly provided by E. Boudon-Padieu (INRA, Dijon, France). CYP and FDP were maintained by Euscelidius variegatus (Kirschbaum) transmission in daisy (Chrysanthemum carinatum Schousboe) and broad bean (Vicia faba L.) plants, respectively.

Healthy colonies of E. variegatus, vector of both CYP (Bosco et al., 1997; 2007) and FDP (Caudwell et al. 1970; Boudon-Padieu et al. 1989), were reared on oat (Avena sativa L.) inside plexiglas and nylon cages in growth chambers at $20-25^{\circ} \mathrm{C}$, photoperiod L16:D8. Healthy leafhopper colonies were never exposed to infected plants and were checked by PCR to be phytoplasma-free.

\section{Acquisition and transmission experiments}

4 Two double infection experiments and two control experiments were carried out. In the first double-infection experiment, about $1503^{\text {rd }}-4^{\text {th }}$ instar nymphs were first allowed to feed on CYP-source daisies for one week. After that, all the insects were confined on FDP-source broad bean for another week. The second doubleinfection experiment was similar but nymphs were first fed on FDP-infected broad bean and then on CYP- 
98 infected daisies. In the two control experiments $3^{\text {rd }}-4^{\text {th }}$ instar nymphs were allowed to feed for one week on 99 CYP-source daisies only or on FDP-source broad bean only. Both CYP and FDP source plants were used for phytoplasma acquisition by E. variegatus soon after symptom appearance, two and five weeks post inoculation, respectively. In all the experiments, at the end of the acquisition access period (AAP) on source

102 plants, ten leafhoppers per plant were caged for serial 3-4 days inoculation access periods (IAP, two IAPs per 103 week) on 2-4 broad bean test plants in the same cage, for transmission until their death (60-80 dpa). All 104 experiments were carried out in climatic chambers with photoperiod 16:8 (1:d), 25-20 ${ }^{\circ} \mathrm{C}$ (1-d). Acquisition 105 and inoculations were performed inside plexigas and nylon cages $(40 \times 40 \times 40 \mathrm{~cm})$. All the transmission 106 experiments were carried out twice, but the data of the two experimental repeats were combined because 107 phytoplasma transmission over time was very similar and leafhoppers became infective at the same dates in 108 the two repeats. Broad bean test plants were exposed to the vectors two weeks after sowing. At 14, 22, 33, 10940,50 and 60 days post acquisition (dpa), 10-20 leafhopper adults from each treatment acquisition were 110 sampled and phytoplasmas were quantified in infected insects as described later. Also for phytoplasma 111 quantification, the insects were sampled in two experiments but the data of the two experimental repeats 112 were combined for statistical analyses since a two-way ANOVA for dpa and repeat revealed no statistically 113 significant interaction between dpa and repeat for all the treatments (CYP only, FDP only, CYP first 114 acquisition, CYP second acquisition, FDP first acquisition, FDP second acquisition). . Test plants exposed to 115 insects were then treated with insecticides and maintained in the greenhouse for 60 days. Broad beans 116 exposed to healthy vectors were used as controls.

117 In a third experiment, to confirm that transmission results were actually due to phytoplasma competition in 118 the insect and not in the recipient plant, about 50 leafhoppers fed on both CYP- and FDP-source plants in 119 both orders as previously described were singly caged for a $24 \mathrm{~h}$ IAP inside $1.5 \mathrm{ml}$ Eppendorf tubes with 120 caps filled with $200 \mu \mathrm{l}$ of an artificial feeding medium (5\% sucrose in TE buffer $\mathrm{pH}$ 8.0, 10mM Tris and 121 1mM EDTA) 35 days after the first acquisition period. At the end of the IAP, feeding medium was collected 122 and analysed for the presence of phytoplasmas as described below. At the same time, surviving insects were 123 collected and salivary glands were dissected and analysed for the presence of phytoplasmas as described 124 below. 
126

127

128

129

130

131

132

133

134

135

136

137

138

139

140

141

142

143

144

145

146

147

148

149

150

151

152

DNA extraction and detection of CYP and FDP by conventional PCR

Leaves of all broad beans exposed to leafhoppers were sampled four weeks after inoculation and total DNA was extracted from CYP and FDP inoculated broad bean leaves $(0.1 \mathrm{~g})$ with the PureLink Plant Total DNA Purification Kit (Invitrogen, Carlsbad, CA, USA) according to the manufacturer protocol and eluted in $50 \mu \mathrm{L}$ of kit elution buffer. Total DNA was extracted with the same protocol from healthy broad beans as control.

Total DNA was also extracted from single leafhoppers sampled at 14, 22, 33, 40, 50 and 60 dpa following a procedure previously described by Marzachì et al. (1998). The same extraction procedure (volume was adjusted according to the smaller size of salivary glands compared with the whole body) was applied to extract DNA from the dissected salivary glands of leafhoppers caged inside Eppendorf tubes to feed on the sucrose feeding medium.

Detection of CYP and FDP by conventional nested PCR was also performed on feeding media collected from Eppendorf tube caps after inoculation with infectious leafhoppers according to Tanne and co-workers (2001). Phytoplasma particles were pelleted out of the feeding solution by centrifugation at $12,000 \mathrm{~g}$ for 15 min, at $4{ }^{\circ} \mathrm{C}$. DNA was extracted by adding $10 \mu \mathrm{l}$ of $0.5 \mathrm{M} \mathrm{NaOH}$, followed by the addition of $20 \mu \mathrm{l}$ of $1 \mathrm{M}$ Tris- $\mathrm{HCl}(\mathrm{pH} 8.0)$ containing 1\% sodium dodecyl sulfate and $20 \mathrm{mM}$ EDTA. The mixture was incubated at $65^{\circ} \mathrm{C}$ for $15 \mathrm{~min}$ and precipitated with 2 volumes of ethanol, and the pellet was dissolved in $30 \mu \mathrm{l}$ of TE. 1.5 $\mu \mathrm{l}$ of this preparation was used as PCR template.

The presence of CYP and FDP in the broad beans, individual leafhoppers, individual salivary glands and feeding media collected from Eppendorf tube caps following insect feeding was assessed by conventional nested PCR using the primers R16F2/R2 followed by R16F1/R1 (I) or (V) (Lee et al., 1993; Lee et al., 1994). Cycling conditions were as detailed in the original papers. The products were separated in a $1 \%$ (wt/vol) agarose gel, buffered in TBE (90 mM Tris borate and 2 mM EDTA, $\mathrm{pH} 8.3$ ), stained with ethidium bromide, and visualized under UV light.

\section{Quantification of phytoplasmas in the insect bodies}

The concentration of DNA in preparations from single E. variegatus extracts was measured with a Nanodrop 1000 spectrophotometer (Thermo Fisher Scientific, Wilmington, DE, USA). 
153 Samples were then diluted in $\mathrm{ddH} 2 \mathrm{O}$ to a final concentration of $1 \mathrm{ng} \mu \mathrm{l}^{-1}$, and $5 \mu \mathrm{l}$ used as template for real154 time assays in a Chromo4 Real-Time PCR (qPCR, Bio-Rad Laboratories, Hercules, CA, USA) thermal 155 cycler, according to Marzachì \& Bosco (2005). Phytoplasma and insect DNAs from the same sample were 156 separately quantified in each plate. The SecY DNA sequence was chosen as target for the amplification of 157 phytoplasma DNAs (Roggia et al., 2013).

158 Absolute quantification of CYP was achieved by comparison of cycle tresholds (Cts) of the samples with 159 those of four dilutions in distilled water of the plasmid pSecYCY (Galetto et al., 2008), containing the CYP $160 \sec \mathrm{Y}$ target sequence $\left(1,09 * 10^{8} 1,09 * 10^{6}, 1,09 * 10^{4}\right.$ copy number/ per $\left.\mu \mathrm{l}\right)$. Absolute quantification of FDP 161 was achieved by comparison of Cts of the samples with those of four dilutions in distilled water of the 162 plasmid pSecYFD containing the FDP $\sec \mathrm{Y}$ target sequence $\left(1,17^{*} 10^{8}, 1,17 * 10^{6}, 1,17^{*} 10^{4}\right.$ copy number/ per $163 \mu \mathrm{l})$. For insect DNA amplification, the $18 \mathrm{~S}$ rDNA sequence was chosen as target and amplified with primer 164 pair $\mathrm{MqFw}$ and $\mathrm{MqRv}$ (Marzachi and Bosco, 2005). Absolute quantification of total insect DNA was 165 achieved by comparison of Cts of the samples with those of three dilutions (10 ng/ $\mu 1,1 \mathrm{ng} / \mu \mathrm{l}, 0.1 \mathrm{ng} / \mu \mathrm{l})$ of 166 healthy insect DNA employed in the qPCR reactions for the standard curve construction.

167 CYP and FDP DNAs were measured as fg of phytoplasma DNA per ng of insect DNA and then transformed 168 into the number of phytoplasma cells per ng of vector DNA as described in the original method (Marzachi 169 and Bosco, 2005) with some modifications: one fg of pSecYFD and pSecYCY plasmids contained 234 and 170219 molecules of plasmids, respectively, each containing a single copy of the $\sec \mathrm{Y}$ gene. As this is a single 171 copy gene in phytoplasma genomes (Oshima et al., 2004), one femtogram of each plasmid corresponded to 172234 and 219 FD or CY cells, respectively.

173 The amplification mix contained $0.3 \mu \mathrm{M}$ of each primer (FD SecY Fw/Rev for FDP; CY SecY Fw/Rev for 174 CYP; Mq Fw/Rev for vector DNA), 1X iQTM SYBR ${ }^{8}$ Green Supermix (Bio-Rad) and templates in a final 175 volume of $25 \mu \mathrm{l}$. Cycling conditions for CYP and insect $18 \mathrm{~S}$ rDNA amplification were as follows: $95^{\circ} \mathrm{C}$ for 3 $176 \min , 63^{\circ} \mathrm{C}$ for $1 \mathrm{~min}$ repeated 45 times, $95^{\circ} \mathrm{C}$ for $1 \mathrm{~min}, 65^{\circ} \mathrm{C}$ for $1 \mathrm{~min}$ for 45 times. For FDP amplification 177 were as follow: $95^{\circ} \mathrm{C}$ for $3 \mathrm{~min}, 61^{\circ} \mathrm{C}$ for $1 \mathrm{~min}$ repeated 45 times, $95^{\circ} \mathrm{C}$ for $1 \mathrm{~min}, 65^{\circ} \mathrm{C}$ for $1 \mathrm{~min}$ for 45 178 times. Specificity of the reaction was tested by running a melting curve analysis of the amplicons following 179 each quantification reaction. In each qPCR plate, DNA from phytoplasma-free insects and water controls 180 were also included. All samples were run in triplicate. CYP and FDP quantification by real time PCR was 
181 applied to the leafhoppers sampled at different times post acquisition that tested positive in nested PCR 182 assays (see table 2). Therefore, sample sizes for phytoplasma titre estimation varied slightly but, on average, 18310 insects per treatment per days after the start of AAP (dpa) were analised.

184

185 Data analysis

186 For the statistical analysis, raw data (number of phytoplasma cells/ ng of total insect DNA) were transformed 187 into the logarithm. To compare the phytoplasma titres measured in individual leafhoppers following the same 188 acquisition conditions at different dpa one-way ANOVA was performed. The same test was applied to 189 compare the phytoplasma titres in the insects following single or mixed infection at different times post190 acquisition (CYP in single and doubly infected insects at 14, 22, 33, 40 and 50 dpa, FDP in single and 191 doubly infected insects at 14, 22, 33, 40 and $50 \mathrm{dpa}$ ). The t-test was applied to compare CYP and FDP titres 192 at each sampling time. The proportion of phytoplasma-positive insects (as determined by PCR) following 193 different acquisition conditions were compared with $\chi^{2}$. Statistical tests were performed with Jandel 194 SigmaPlot 11.0 (Systat Software, Inc, San Jose, CA USA).

195

196

197

198

199

200

201

202

203 204 205 206 207 208

\section{Results}

Symptoms of CYP-and FDP-infected broad beans

Broad bean plants developed different symptoms following inoculations with CYP or FDP by the vector $E$. variegatus. CYP induced thickening and vein yellowing of the basal leaves while FDP induced upward leaf roll of younger leaves with a variable level of yellowing of the same leaves (Supplementary Figure S1A and B). Symptoms induced by the two phytoplasmas were the same both in single- and doubly-infected plants and these latter showed CYP symptoms on the basal leaves and FDP symptoms on the apical ones. Symptoms of CYP infection appeared consistently earlier than symptoms of FDP: 15-18 versus 28-30 dpi.

\section{CYP and FDP transmission}

Infection of all the test plants was established by species-specific PCR assays for both phytoplasmas. Symptom development was in agreement with results of PCR detection. The total number of plants infected by CYP and FDP, following single and double acquisitions, are summarised in table 1. Only transmission 
209 experiments carried out from 28 days post acquisition (dpa) onwards were considered in table 1 as most of 210 the leafhoppers were not yet infectious (latent period was not completed) in earlier transmission tests 211 (Supplementary table S2). Figure 1 describes the transmission of CYP (A) and FDP (B) over time by $E$. 212 variegatus following different acquisition conditions. E. variegatus transmitted CYP from 17-21 dpa and 213 FDP from 28 dpa onwards. The vector transmitted both phytoplasmas until its death. When E. variegatus 214 was allowed to acquire both phytoplasmas, CYP transmission was not affected by the concurrent acquisition 215 of $\operatorname{FDP}\left(\chi^{2}=0,764\right.$ with 2 d.f., $\left.\mathrm{P}=0,682\right)$ while FDP transmission was suppressed in the presence of CYP $216\left(\chi^{2}=71,222\right.$ with 2 d.f., $\left.\mathrm{P}<0,001\right)$ (Table 1$)$. The rate of CYP transmission to broad bean was always greater 217 than 75\%, but the rate of FDP transmission was significantly lower after FDP-only acquisition (7-16\%) than 218 after FDP+CYP acquisition (62\%)..

\section{CYP and FDP acquisition}

The numbers of leafhoppers that acquired CYP and/or FDP following single and double AAPs are 222 summarized in Table 2. E. variegatus acquired CYP with higher efficiency than it acquired FDP, both 223 following a single $\operatorname{AAP}\left(\chi^{2}=11.48\right.$ with 1 d.f.; $\left.\mathrm{P}=0.003\right)$ and two subsequent $\mathrm{AAPs}\left(\chi^{2}=40.952\right.$ with 2 d.f.; $224 \mathrm{P}<0.001)$. The proportion of leafhoppers that became CYP-infected was significantly lower in treatments 225 providing exposure to both phytoplasmas (FDP $+\mathrm{CYP})$ than treatments containing only CYP. $\left(\chi^{2}=11.480\right.$ 226 with 2 d.f.; $\mathrm{P}=0.003$ ). A similar phenomenon seemed to occur for $\mathrm{FDP}$, though the difference was not 227 significant $\left(\chi^{2}=5.022\right.$ with 2 d.f.; $\left.\mathrm{P}=0.081\right)$. E. variegatus acquired CYP with higher efficiency if it fed 228 first on FDP and then CYP than if it was exposed to the two phytoplasmas in the opposite order. $(\chi 2=4.891$ 229 with 1 d.f.; $\mathrm{P}=0,027)$. On the contrary, acquisition of FDP was not influenced by feeding order $(\chi 2=0.153$ 230 with 1 d.f.; $\mathrm{P}=0.696$ ).

\section{CYP and FDP titres in infected Euscelidius variegatus}

233 CYP titre in E. variegatus, as determined in qPCR, ranged from about three thousand cells per ng of insect 234 DNA at $14 \mathrm{dpa}$, up to a few tens of thousands of cells at later stages in the infection process (Figure 2). One235 way ANOVA for CYP titre over time showed a significant increase $(\mathrm{P}<0.001)$. CYP concentration was not 236 influenced by the acquisition conditions. One-way ANOVA for CYP titre (14, 22, 33, 40 and 50 dpa) always 
237 indicated that CYP concentration was the same, irrespective of the acquisition conditions (single or double).

238 FDP titre in E. variegatus ranged from one thousand cells per ng of insect DNA at 14 dpa to a few hundred 239 thousand cells later in the infection process. One-way ANOVA for FDP titre over time showed a significant 240 increase $(\mathrm{P}<0.001)$. FDP titre was influenced by the acquisition conditions (single or double)- Following 241 double acquisition, at 14 and $22 \mathrm{dpa}$ an increase in FDP titre was recorded $(\mathrm{P}=0.045$ and $\mathrm{P}=0.047$, 242 respectively), while at $33 \mathrm{dpa}$ a decrease was recorded $(\mathrm{P}=0.040)$. Later in the infection process FDP titres 243 measured in single or doubly-infected insects did not differ significantly. Leafhoppers infected by FDP 244 hosted a higher phytoplasma titre compared to those infected by CYP. This higher FDP titre was recorded 245 both in singly ( $22 \mathrm{dpa}, \mathrm{P}=0.004 ; 33 \mathrm{dpa}, \mathrm{P}<0.001 ; 40 \mathrm{dpa}, \mathrm{P}=0.017 ; 50 \mathrm{dpa}, \mathrm{P}=0.005$ ) and doubly-infected 246 (22 dpa, $\mathrm{P}=0.015 ; 33$ dpa, $\mathrm{P}=0.004 ; 40$ dpa, $\mathrm{P}<0.001 ; 50 \mathrm{dpa}, \mathrm{P}=0.048$ ) insects from 22 dpa onwards (Figure 247 2, Supplementary table S3).

CYP and FDP detection in salivary glands and artificial feeding media

250 The two phytoplasmas colonized the salivary glands with with significantly different efficiencies. Following 251 CYP + FDP acquisitions, 23/24 and 3/24 leafhoppers had CYP- and FDP-positive salivary glands, 252 respectively. Following FDP + CYP acquisitions, 15/16 and 3/16 leafhoppers had phytoplasma-positive 253 salivary glands to CYP and FDP, respectively. Consistently, CYP was detected by PCR in 11/24 feeding 254 media following CYP + FDP acquisitions and in 7/16 feeding media following the FDP + CYP acquisition, 255 while FDP was never detected in feeding media (Table 3).

257 Discussion

258 The competition between two unrelated phytoplasma species within the leafhopper vector E. variegatus was 259 studied following serial acquisition of the vector on plants singly infected by the chrysanthemum yellows 260 strain of the ' $C a$. P. asteris' (CYP) and the Flavescence dorée phytoplasma (FDP). The two phytoplasmas 261 were chosen as they can be both transmitted by E. variegatus to broad bean plants, although, as this 262 leafhopper is not the natural vector of FDP, the possibility that interactions between naturally occurring 263 phytoplasmas might be different cannot be excluded. In particular, CYP and FDP induced distinctive 264 symptoms in the basal and apical parts of the infected plants, respectively, and doubly infected broad beans 
265 showed both symptoms. Symptom expression in each phytoplasma - plant combination may differ due to the 266 presence of different phytoplasma effector proteins (Sugio et al., 2011) and different plant responses to them. 267 E. variegatus transmitted CYP after a shorter LP than FDP, in line with previous experiments (this group, 268 unpublished). Also, E. variegatus transmitted CYP more efficiently than FDP after exposure to singly 269 infected plants, and CYP transmission was not influenced by FDP, irrespective of the sequence of 270 acquisition. On the other hand, FDP transmission was severely reduced by the acquisition of CYP, 271 irrespective of the order of exposure to both sources. A similar situation was reported for Dalbulus maidis 272 where prolonged acquisition of corn stunt spiroplasma suppressed maize bushy stunt phytoplasma 273 transmission (Maramorosch, 1958), and for the vector Macrosteles quadrilineatus (=fascifrons) where the 274 majority of the leafhoppers transmitted only the first phytoplasma to which they had access when allowed to 275 acquire different strains of aster yellows phytoplasmas (Freitag, 1967). In these previous studies, the absence 276 of molecular tools hampered the analyses of other analyses of aspects of the competition between mollicutes 277 other than transmission. In this study, competition was not recorded at the acquisition level, as FDP 278 acquisition efficiency was not affected by CYP in double acquisition trials, while a slight decrease was 279 observed in CYP acquisition when E. variegatus was also exposed to FDP. When the titre of both 280 phytoplasmas was measured within the vector body, both microorganisms actively multiplied in singly 281 infected vectors, and FDP reached a much higher concentration than CYP. In the presence of CYP, FDP titre 282 seemed to be suppressed but this effect was significant only at $33 \mathrm{dpa}$. In contrast, CYP multiplication over 283 time was not affected by the presence of FDP and also CYP titre was not influenced by co-acquisition of 284 FDP. These results indicate an unilateral competition of the two phytoplasmas within the insect body, where 285 the presence of CYP seemed to hamper the multiplication of FDP and limit the number of FDP cells in the 286 vector. Despite this competition, FDP reached higher concentration compared to CYP at later stages of 287 infection (from 22 dpa onwards) in doubly infected vectors. However, it is important to note that FDP was 288 unable to colonize the salivary glands and reach the saliva of doubly infected vectors as it was only 289 sporadically detected in dissected salivary glands of E. variegatus following exposure to CYP and FDP290 infected plants, in both orders, and it was never detected in the artificial medium following inoculation. This 291 suggests that salivary glands are the barrier where competition between CYP and FDP prevents efficient 292 FDP transmission by E. variegatus. It can be suggested that the phytoplasma having the shorter latent period 
293 in the vector, CYP, is the first to colonize salivary glands and therefore is the most competitive for

294 transmission. In this case, salivary glands already colonized by a phytoplasma might not be available for 295 further invasion by a second one. FDP showed a more active multiplication in the insect body, but it did not 296 suppress CYP multiplication. Therefore, the speed of salivary glands colonization, rather than the level of 297 multiplication, is likely to be the key factor for successful transmission. This hypothesis may also explain the 298 suppression of maize bushy stunt phytoplasma (MBSP) by corn stunt spiroplasma (CSS) in the vector $D$.

299 maidis: CSS may move more rapidly in the insect body, thus suppressing transmission of MBSP

300 (Maramorosch, 1958). CYP transmission depends on phytoplasma titre in the salivary glands of $E$.

301 variegatus, as non-transmitter individuals host only a few hundred CYP cells per ng of insect DNA in their 302 salivary glands while transmitters host thousands of cells (Galetto et al., 2009), therefore a high titre of 303 phytoplasma in the salivary glands seems to be a prerequisite for efficient transmission. The erratic presence 304 of FDP in the salivary glands of E. variegatus exposed subsequently to CYP and FDP and the absence from 305 saliva (feeding media) also ruled out phytoplasma competition in the inoculated plants as possible cause of 306 the failure of FDP transmission to broad bean. A correlation between phytoplasma titre and transmission 307 efficiency occurs for CYP and two of its natural vectors: Macrosteles quadripunctulatus sustains a higher 308 phytoplasma multiplication compared to E. variegatus, and it is also the most efficient vector (Bosco et al., 309 2007). The same correlation does not apply to FDP and CYP transmission by E. variegatus, since this vector 310 sustains a higher FDP multiplication compared to CYP but transmits the latter more efficiently. This 311 apparent contradiction may be explained by the competition for the colonization of the salivary glands when 312 two phytoplasmas co-infect the same individual. From an evolutionary perspective, the phytoplasma 313 colonizing salivary glands first would obtain a fitness gain compared to a slower one (the faster, the fitter).

314 The different behaviour of the two phytoplasmas may also be explained by the interactions with the insect 315 host, besides competition between the phytoplasmas. The host immune system may recognize and suppress 316 the CYP, or the CYP may have developed mechanisms to invade the salivary glands during the long-term 317 relationship of the insect host and the phytoplasma.

318 CYP, as the other aster yellows strains, has a broad host range and therefore it is very likely that in an 319 evolutionary time scale it interacted with several different vector species. On the contrary, FDP has a very 320 narrow host range (grapevine and very few alternative hosts) and it is not likely to be co-evolved with 
321 different vector species. This may contribute to explain why CYP is more competitive for transmission in $E$.

322 variegatus.

323 In summary, E. variegatus transmitted CYP with high efficiency and it was not influenced by the presence of 324 FDP, and CYP was able to colonize the salivary glands and reach saliva, consistent with the high efficient 325 transmission results. On the other hand, the good efficacy of E. variegatus as vector of FDP following single 326 acquisition was significantly lower when competition with CYP was introduced, although FDP persisted for 327 life within the vector. E. variegatus is a natural vector of CYP (Bosco et al., 1997; Palermo et al., 2001), 328 while it transmits FDP under laboratory conditions only, as it is not able to feed on grape, the natural host 329 plant of FDP. In the case of E. variegatus-CYP association, both partners are of Palaearctic origin and 330 therefore co-evolved for a long time so that phytoplasma multiplication is mitigated and no pathogenic 331 effects are recorded (D'Amelio et al., 2008). In contrast, the association between FDP and E. variegatus is 332 artificial and this can explain the phytoplasma low ability to colonize the salivary glands (needed for 333 transmission) and also its high multiplication in the vector, which causes severe pathogenic effects (Bressan 334 et al., 2005). Nevertheless, even the "natural" vector of FDP, Scaphoideus titanus Ball, is not long co335 evolved with FDP because the leafhopper is of Nearctic origin (Bertin et al., 2007) while FDP is very likely 336 of Palaearctic origin (Arnaud et al., 2007). Therefore, it is possible that the same phenomenon also occurs in 337 S. titanus, but further studies are needed to demonstrate this.

338 In nature, polyphagous vectors have chances of acquiring different phytoplasmas by visiting and feeding on 339 different host plants. This work, together with those of Freitag (1967) on related strains of aster yellows 340 phytoplasmas infecting M. quadrilineatus, Maramorosch (1958) and de Oliveira and co-workers (2007) on 341 different mollicutes within D. maidis, indicates that interactive transmission (up to unilateral suppression) is 342 more common than non-interactive transmission, as this latter has not been reported so far for phytoplasmas.

343 Interestingly, unilateral suppression occurs between both genetically related (Freitag, 1967) and un-related 344 phytoplasmas (this work). This is the first time that interaction / competition of different phytoplasmas has 345 been described and dissected at the acquisition, multiplication, body colonization and transmission levels.

346 The role of interactive transmission in nature must be taken into account for the description and prediction of 347 phytoplasma epidemiology, as different phytoplasmas are likely to be present in different environments and 
348 interactive transmission may contribute to explain differential spread of the same phytoplasma in the same 349 crop under different environmental conditions.

350

351

352

353

354

355

356

357

358

359

360

361

362

363

364

365

366

367

368

369

370

371

372

373

374

\section{Acknowledgements}

MR was supported by a grant from Piedmont Region within the project "FLADO", RD'A was supported by a grant from Piedmont Region within the project "Valutazione dell'azione di microrganismi rizosferici ed elicitori di resistenza sull'infezione da fitoplasmi in un sistema modello (CIPE 2006).

\section{References}

Arnaud G., Malembic-Maher S., Salar P, Bonnet P, Maixner M., Marcone C., Boudon-Padieu E., Foissac X. (2007) Multilocus Sequence Typing Confirms the Close Genetic Interrelatedness of Three Distinct Flavescence Dorée Phytoplasma Strain Clusters and Group 16SrV Phytoplasmas Infecting Grapevine and Alder in Europe. Applied and Environmental Microbiology, 73, 40014010.

Bertin S., Guglielmino C.R., Karam N., Gomulski L:M:, Malacrida A.R., Gasperi G. (2007) Diffusion of the Nearctic leafhopper Scaphoideus titanus Ball in Europe: a consequence of human trading activity. Genetica, 131, 275-285.

Bosco D., D’Amelio R. (2010) Transmission specificity and competition of multiple phytoplasmas in the insect vector. In Phytoplasmas: genomes, plant hosts, and vectors, 293-308. Weintraub, P., and Jones, P. (eds). Wallingford, UK: CAB International.

Bosco D., Minucci C., Boccardo G., Conti M. (1997) Differential acquisition of Chrysanthemum yellows phytoplasma by three leafhopper species. Entomologia Experimentalis et Applicata, 83, 219-224.

Bosco D., Galetto L., Leoncini P., Saracco P., Raccah B., Marzachi C. (2007) Interrelationships between "Candidatus Phytoplasma asteris" and its leafhopper vectors. Journal of Economic Entomology, 100, 1504-1511. 
375 Boudon-Padieu E., Larrue J., Caudwell A. (1989) ELISA and Dot-Blot detection of Flavescence 376 dorée MLO in individual leafhopper vectors during latency and inoculative state. Current 377 Microbiology, 19, 357-364.

378 Bressan A., Girolami V., Boudon-Padieu E. (2005) Reduced fitness of the leafhopper vector 379 Scaphoideus titanus exposed to Flavescence doree phytoplasma. Entomologia Experimentalis et $380 \quad$ Applicata, 115, 283-290.

381 Caudwell A., Kuszala C., Larrue J., Bachelier J.C. (1970) Transmission de la Flavescence dorée de 382 la fève à la fève par des cicadelles des genres Euscelis et Euscelidius. Intervention possible de 383 ces insectes dans l'épidémiologie du bois noir en Bourgogne. Annales de Phytopathologie, $\mathbf{n}^{\circ}$ 384 hors série, 181-189.

385 Conti M., D’Agostino A., Casetta A., Mela L. (1988) Some characteristics of Chrysanthemum 386 yellows disease. Acta Horticulturae, 234, 129-136.

387 D'Amelio R., Marzachì C., Bosco D. (2007) Double infection of 'Candidatus Phytoplasma asteris' 388 and "flavescence doree" phytoplasma in the vector Euscelidius variegatus. Bulletin of 389 Insectology, 60, 223-224.

390 D'Amelio R., Palermo S., Marzachì C., Bosco D. (2008) Influence of Chrysanthemum yellows 391 phytoplasma on the fitness of two of its leafhopper vectors, Macrosteles quadripunctulatus and 392 Euscelidius variegatus. Bulletin of Insectology, 61, 349-354.

393 de Oliveira E., Santos J.C., Magalhaes P.C., Cruz I. (2007) Maize bushy stunt phytoplasma 394 transmission by Dalbulus maidis is affected by spiroplasma acquisition and environmental 395 conditions Bulletin of Insectology, 60, 229-230.

396 Foissac X., Wilson M.R. (2010) Current and possible future distributions of phytoplasma diseases 397 and their vectors. In Phytoplasmas: genomes, plant hosts, and vectors, 309-324. Weintraub, P., 398 and Jones, P. (eds). Wallingford, UK: CAB International.

399 Freitag J.H. (1967) Interaction between strains of aster yellows virus in the six-spotted leafhopper $400 \quad$ Macrosteles fascifrons. Phytopathology, 57, 1016-1024. 
401 Galetto L., Fletcher J., Bosco D., Turina M., Wayadande A., Marzachì C. (2008) Characterization 402 of putative membrane protein genes of the 'Candidatus Phytoplasma asteris', Chrysanthemum 403 yellows isolate. Canadian Journal of Microbiology, 54, 341-351.

404 Galetto L., Nardi M., Saracco P., Bressan A., Marzachì C., Bosco D. (2009) Variation in vector 405 competency depends on Chrysanthemum yellows phytoplasma distribution within Euscelidius 406 variegatus. Entomologia Experimentalis et Applicata, 131, 200-207.

407 Gratz N.G. (1999) Emerging and resurging vector-borne diseases. Annual Review of Entomology, $408 \quad 44,51-75$.

409 Hogenhout S.A., Oshima K., Ammar E.D., Kakizawa S., Kingdom H.N., Namba S. (2008) 410 Phytoplasmas: bacteria that manipulate plants and insects. Molecular Plant Pathology, 9, 403411423.

412 Hsu T.P., Banttari E.E. (1979) Dual transmission of the aster yellows mycoplasma-like organism 413 and the oat blue dwarf virus and its effect on longevity and fecundity of the aster leafhopper $414 \quad$ vector. Phytopathology, 69, 843-845.

415 Kuske C. R., Kirkpatrick B.C.. (1992) Distribution and multiplication of western aster yellows 416 mycoplasmalike organisms in Catharanthus roseus as determined by DNA hybridization 417 analysis. Phytopathology, 82, 457-462.

418 Lee I.M., Davis R.E., Hsu H.T. (1993) Differentiation of Strains in the Aster Yellows 419 Mycoplasmalike Organism Strain Cluster by Serological Assay with Monoclonal-Antibodies. $420 \quad$ Plant Disease, 77, 815-817.

421 Lee I.M., Davis R.E., Gundersen-Rindal D.E. (2000) Phytoplasma: Phytopathogenic mollicutes. 422 Annual Review Microbiology, 54, 221-255.

423 Lee I.M., Gundersen D.E., Hammond R.W., Davis R.E. (1994) Use of Mycoplasmalike Organism 424 (MLO) Group-Specific Oligonucleotide Primers for Nested-Pcr Assays to Detect Mixed-MLO 425 Infections in a Single Host-Plant. Phytopathology, 84, 559-566. 
426 Maramorosch K. (1958) Cross-protection between two strains of corn stunt virus in an insect vector. 427 Virology, 6, 448-459.

428 Martini M., Botti S., Marcone C., Marzachì C., Casati P., Bianco P.A. et al. (2002) Genetic 429 variability among flavescence doree phytoplasmas from different origins in Italy and France. $430 \quad$ Molecular and Cellular Probes, 16, 197-208.

431 Marzachì C., Bosco D. (2005) Relative quantification of Chrysanthemum yellows (16Sr I) 432 phytoplasma in its plant and insect host using real-time polymerase chain reaction. Molecular 433 Biotechnology, 30, 117-127.

434 Marzachì C., Veratti F., Bosco D. (1998) Direct PCR detection of phytoplasmas in experimentally 435 infected insects. Annals of Applied Biology, 133, 45-54.

436 Marzachì C., Palermo S., Boarino A., Veratti F., d'Aquilio M., Loria A., Boccardo G. (2001) 437 Optimisation of a one-step PCR assay for the diagnosis of Flavescence doreerelated 438 phytoplasmas in field-grown grapevines and vector populations. Vitis, 40, 213-217.

439 Oshima K., Kakizawa S., Nishigawa H., Jung H.Y., Wei W., Suzuki S. et al. (2004) Reductive 440 evolution suggested from the complete genome sequence of a plant-pathogenic phytoplasma. $441 \quad$ Nature Genetics, 36, 27-29.

442 Palermo, S., Arzone, A., and Bosco, D. (2001) Vector-pathogen-host plant relationships of 443 Chrysanthemum yellows (CY) phytoplasma and the vector leafhoppers Macrosteles 444 quadripunctulatus and Euscelidius variegatus. Entomologia Experimentalis Applicata, 99, 347445354.

446 Purcell A.H. (1982) Insect vector relationships with prokaryotic plant pathogens. Annual Review of $447 \quad$ Phytopathology, 20, 397-417.

448 Roggia C., Caciagli P., Galetto L., Pacifico D., Veratti F., Bosco D., Marzachì C. (2013) 449 Flavescence dorée phytoplasma titre in field-infected Barbera and Nebbiolo grapevines. Plant $450 \quad$ Pathology, 63, 31-41. 
451 Seemueller E., Kiss E., Sandor S., Schneider B. (2010) Multiple infection of apple trees by distinct 452 strains of 'Candidatus Phytoplasma mali' and its pathological relevance. Phytopathology, 100, $453 \quad 863-870$.

454 Sinclair W.A., Gleason M.L., Griffiths H.M., Iles J.K., Zriba N., Charlson D.V., Batzer J.C. (2000) 455 Responses of 11 Fraxinus cultivars to ash yellows phytoplasma strains of differing 456 aggressiveness. Plant Disease, 84, 725-730.

457 Sugio A., Maclean A.M., Kingdom H.N., Grieve V.M., Manimekalai R., Hogenhout S.A. (2011) 458 Diverse targets of phytoplasma effectors: from plant development to defense against insects. 459 Annual Review of Phytopathology, 49, 175-195.

460 Tanne E., Boudon-Padieu E., Clair D., Davidovich M., Melamed S., and Klein M. (2001) Detection 461 of phytoplasma by polymerase chain reaction of insect feeding medium and its use in 462 determining vectoring ability. Phytopathology, 91, 741-746.

463 Weintraub, P.G., Beanland L. (2006) Insect vectors of phytoplasmas. Annual Review of $464 \quad$ Entomology, 51, 91-111.

465

466 Table and Figure legends

467 Table 1. Results of transmission experiments of chrysanthemum yellows (CYP) and Flavescence 468 dorée (FDP) phytoplasmas with Euscelidius variegatus to broad bean plants. Number of 469 infected/exposed plants as determined by species-specific nested PCR are reported, following single 470 (CYP only; FDP only) and double (CYP + FDP; FDP + CYP) acquisitions. Group transmissions for 471 3-4 day IAPs from 28 dpa onwards. AAP, acquisition access period. Within columns, figures 472 followed by the same letter do not differ significantly $\left(\chi^{2}\right.$ test). 473

474 Table 2. Results of acquisition experiments of Euscelidius variegatus following AAP on 475 chrysanthemum yellows (CYP) and Flavescence dorée (FDP) -infected broad bean plants. Number 476 of infected leafhoppers are reported following single (CYP only; FDP only) and double (CYP + 
477 FDP; FDP + CYP) acquisitions as determined by species-specific nested-PCR tests. AAP, 478 acquisition access period. Within columns, figures followed by the same letter do not differ 479 significantly $\left(\chi^{2}\right.$ test $)$.

480

481 Table 3. PCR detection (presence: +; absence: -) of chrysanthemum yellows phytoplasma (CYP) 482 and Flavescence dorée phytoplasma (FDP) in salivary glands of single Euscelidius variegatus and 483 in corresponding sucrose feeding media following feeding on CYP- and FDP-infected source plants 484 in both orders. The analysis was carried out 35 days post acquisition. Each line corresponds to a 485 single insect.

486

487 Figure 1. Results of phytoplasma transmission experiments with Euscelidius variegatus. A:

488 chrysanthemum yellows phytoplasma (CYP) transmission following acquisition on CYP-infected 489 plants or on CYP- and Flavescence dorée phytoplasma (FDP)- infected source plants. B: FDP 490 transmission following acquisition on FDP-infected plants or on CYP- and FDP- infected source 491 plants. AAP, acquisition access period.

492

493 Figure 2. Mean \pm SE quantities of chrysanthemum yellows (CYP) and Flavescence dorée (FDP) 494 phytoplasmas (log of cells per ng of insect DNA) measured at different days post acquisition in 495 Euscelidius variegatus leafhoppers fed on CYP source only, FDP source only, CYP followed by 496 FDP (CYP + FDP) and FDP followed by CYP (FDP + CYP).

497

498 Supplementary Figure S1. Symptoms of chrysanthemum yellows (A) and Flavescence dorée (B) 499 phytoplasmas on broad bean plants.

500

501 Supplementary TableS2. Results of chrysanthemum yellows (CYP) and Flavescence dorée (FDP) 502 phytoplasma transmission experiments with Euscelidius variegatus following acquisition on CYP- 
503 infected plants, on FDP-infected plants, or on both source plants. Number of phytoplasma infected

504 plants over exposed ones are reported, as determined by species-specific nested-PCR tests. AAP,

505 acquisition access period.

506

507 Supplementary TableS3. Summary of the statistical analyses performed on the phytoplasma titres

508 measured by R-PCR in Euscelidius variegatus individual leafhoppers following different

509 phytoplasma acquisition conditions. Raw data (phytoplasma cells/ng of total insect DNA) were

510 transformed into the logarithm for the analyses.

511

512 
513 Table 1. Transmission of chrysanthemum yellows (CYP) and Flavescence dorée (FDP)

514 phytoplasmas. Numbers of infected/exposed plants as determined by species-specific nested PCR

515 are reported, following single (CYP only; FDP only) and double (CYP + FDP; FDP + CYP)

516 acquisitions. Group transmissions for 3-4 day IAPs from 28 dpa onwards. AAP, acquisition access

517 period. Within columns, figures followed by the same letter do not differ significantly ( $\chi 2$ test). 518

\begin{tabular}{ccc}
\hline Acquisition source & $\begin{array}{c}\text { CYP transmission } \\
\text { positive/exposed plants } \\
\text { (\% of infected plants) }\end{array}$ & $\begin{array}{c}\text { FDP transmission } \\
\text { positive/exposed plants } \\
\text { (\% of infected plants) }\end{array}$ \\
\hline CYP only (7-day AAP) & $51 / 64(79.7 \%) \mathrm{a}$ & - \\
FDP only (7-day AAP) & - & $67 / 108(62.0 \%) \mathrm{a}$ \\
CYP + FDP (two 7-day AAPs) & $53 / 68(77.9 \%) \mathrm{a}$ & $5 / 68(7.4 \%) \mathrm{b}$ \\
FDP + CYP (two 7-day AAPs) & $56 / 76(76.3 \%) \mathrm{a}$ & $12 / 76(15.8 \%) \mathrm{b}$ \\
\hline
\end{tabular}

519

520 
521 Table 2. Acquisition of phytoplasmas by Euscelidius variegatus following AAP on chrysanthemum

522 yellows (CYP) and Flavescence dorée (FDP) -infected broad bean plants. Number of infected

523 leafhoppers are reported following single (CYP only; FDP only) and double (CYP + FDP; FDP +

524 CYP) acquisitions as determined by species-specific nested-PCR tests. AAP, acquisition access

525 period. PCR assays were carried out on insects sampled from 35 to 60 days post acquisition. Within

526 columns, figures followed by the same letter do not differ significantly ( $\chi 2$ test).

527

\begin{tabular}{ccc}
\hline Acquisition source & $\begin{array}{c}\text { CYP acquisition } \\
\text { positive/tested } \\
\text { (\% of infected } \\
\text { leafhoppers) }\end{array}$ & $\begin{array}{c}\text { FDP acquisition } \\
\text { positive/tested } \\
\text { (\% of infected } \\
\text { leafhoppers) }\end{array}$ \\
\hline CYP only (7-day AAP) & $54 / 59(91.5 \%) \mathrm{a}$ & - \\
FDP only (7-day AAP) & - & $46 / 69(66.7 \%) \mathrm{a}$ \\
CYP + FDP (two 7-day AAPs) & $75 / 105(71.4 \%) \mathrm{b}$ & $44 / 89(49.4 \%) \mathrm{a}$ \\
FDP + CYP (two 7-day AAPs) & $103 / 122(84.4 \%) \mathrm{c}$ & $57 / 107(53.3 \%) \mathrm{a}$ \\
\hline
\end{tabular}

528

529 
530 Table 3. PCR detection (presence: +; absence: -) of chrysanthemum yellows phytoplasma (CYP)

531 and Flavescence dorée phytoplasma (FDP) in salivary glands of single Euscelidius variegatus and

532 in corresponding sucrose feeding medium following feeding on CYP- and FDP-infected source

533 plants in both sequences. The analysis was carried out 35 days post acquisition. Each line

534 corresponds to a single insect.

\begin{tabular}{|c|c|c|c|c|c|c|c|c|c|}
\hline \multicolumn{5}{|c|}{ Acquisition access on CYP followed by FDP } & \multicolumn{5}{|c|}{ Acquisition access on FDP followed by CYP } \\
\hline \multirow[t]{2}{*}{ Insect number } & \multicolumn{2}{|c|}{$\begin{array}{c}\text { Salivary } \\
\text { gland }\end{array}$} & \multicolumn{2}{|c|}{$\begin{array}{l}\text { Feeding } \\
\text { medium }\end{array}$} & \multirow[t]{2}{*}{ Insect number } & \multicolumn{2}{|c|}{$\begin{array}{c}\text { Salivary } \\
\text { gland }\end{array}$} & \multicolumn{2}{|c|}{$\begin{array}{l}\text { Feeding } \\
\text { medium }\end{array}$} \\
\hline & CYP & FDP & CYP & FDP & & CYP & FDP & CYP & FDP \\
\hline 1 & + & + & - & - & 1 & + & - & - & - \\
\hline 2 & + & - & - & - & 2 & + & - & + & - \\
\hline 3 & + & - & + & - & 3 & + & - & + & - \\
\hline 4 & + & - & - & - & 4 & + & - & - & - \\
\hline 5 & + & - & + & - & 5 & + & - & - & - \\
\hline 6 & + & - & + & - & 6 & + & - & + & - \\
\hline 7 & + & - & - & - & 7 & + & - & + & - \\
\hline 8 & + & - & - & - & 8 & + & + & - & - \\
\hline 9 & + & - & - & - & 9 & + & - & - & - \\
\hline 10 & + & - & + & - & 10 & + & + & - & - \\
\hline 11 & + & - & + & - & 11 & + & - & + & - \\
\hline 12 & + & + & - & - & 12 & - & + & - & - \\
\hline 13 & + & + & - & - & 13 & + & - & - & - \\
\hline 14 & + & - & + & - & 14 & + & - & + & - \\
\hline 15 & + & - & + & - & 15 & + & - & - & - \\
\hline 16 & + & - & - & - & 16 & + & - & + & - \\
\hline 17 & + & - & - & - & & & & & \\
\hline 18 & + & - & + & - & & & & & \\
\hline 19 & + & - & - & - & & & & & \\
\hline 20 & - & - & - & - & & & & & \\
\hline 21 & + & - & + & - & & & & & \\
\hline 22 & + & - & + & - & & & & & \\
\hline 23 & + & - & + & - & & & & & \\
\hline 24 & + & - & - & - & & & & & \\
\hline
\end{tabular}


Figure 1.
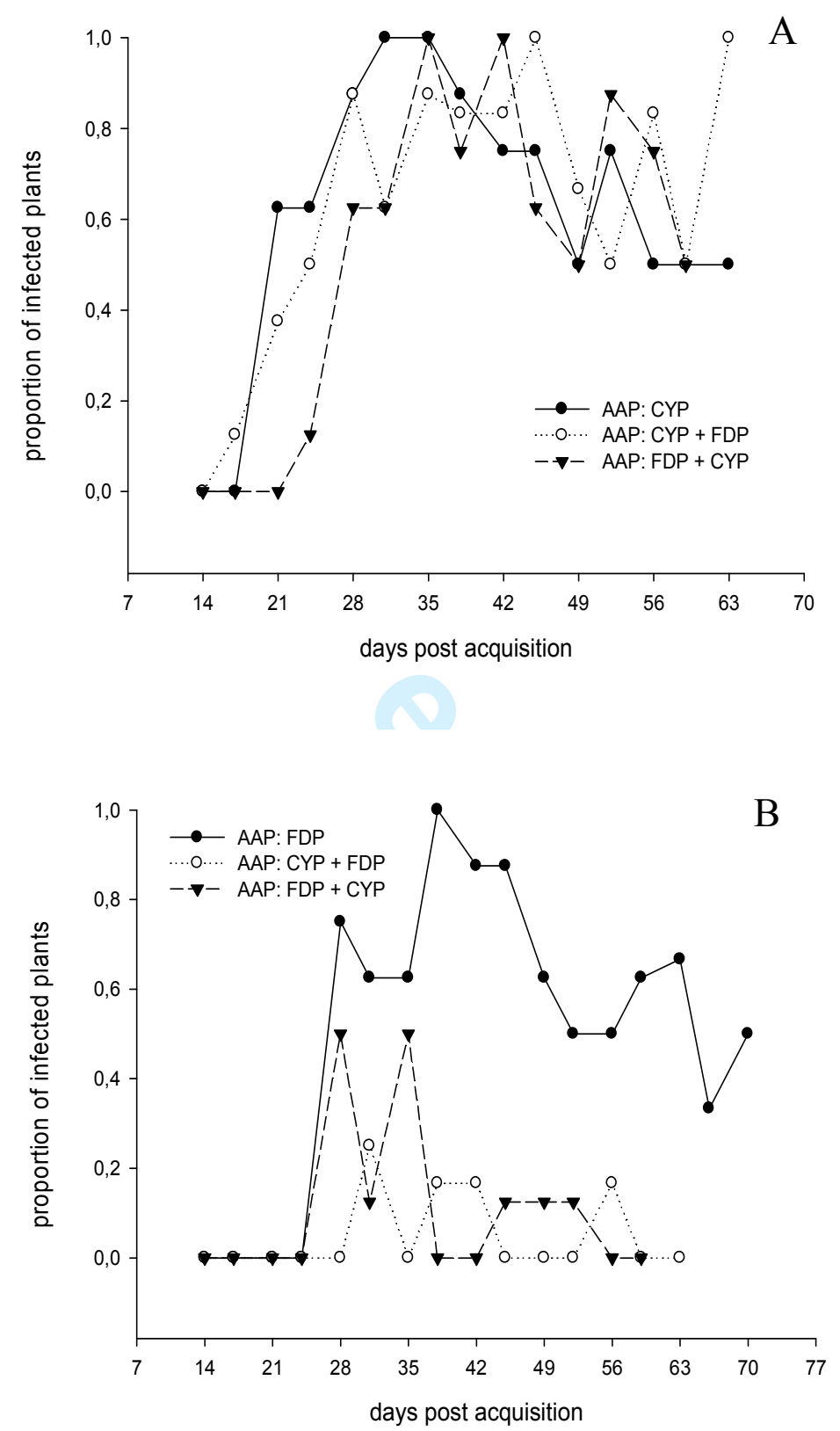
Figure 2
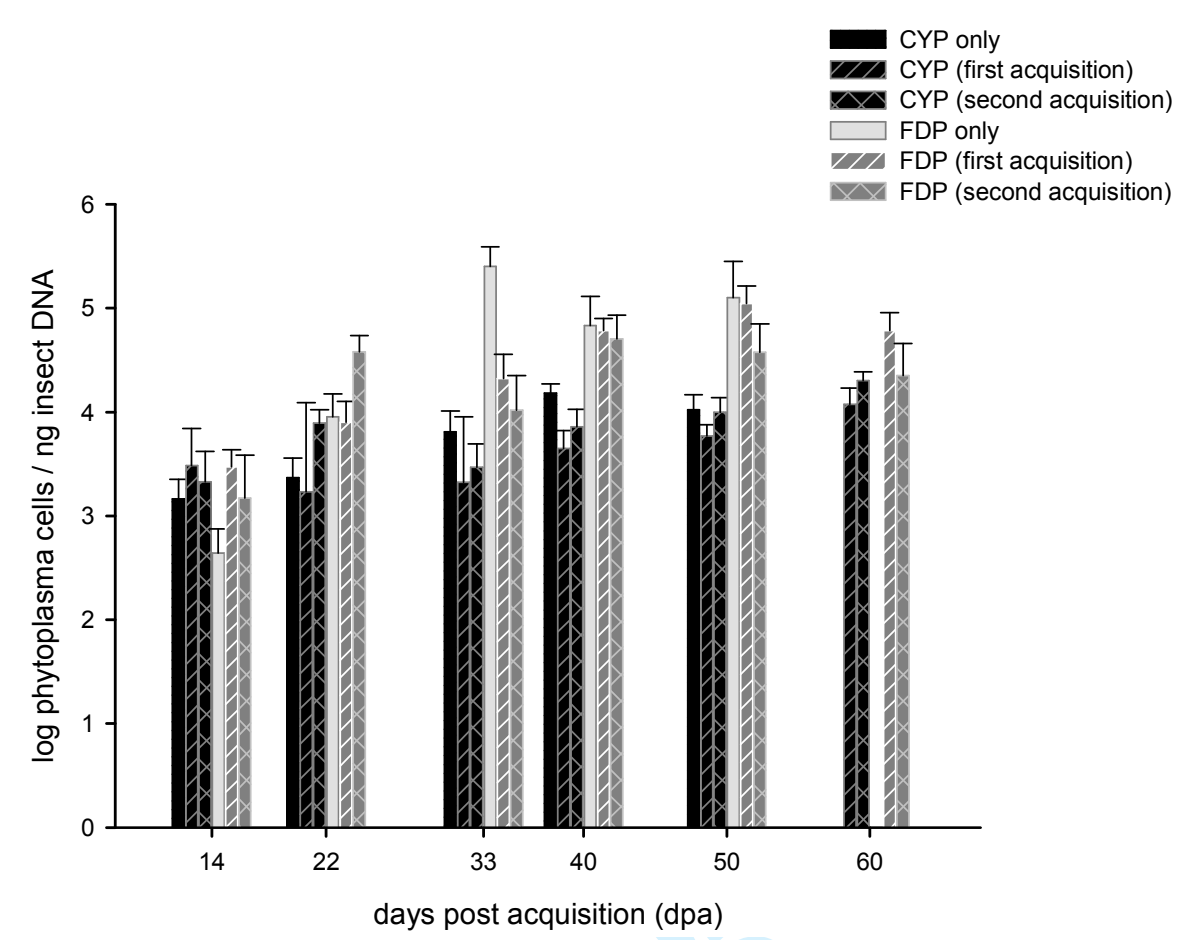

29

30

31

32

33

34

35

36

37

38

39

40

41

42

43

44

45

46

47

48

49

50

51

52

53

54

55

56

57

58

59

60 